\title{
2D-electrophoresis and multiplex immunoassay proteomic analysis of different body fluids and cellular components reveal known and novel markers for extended fasting
}

Freek G Bouwman', Baukje de Roos², Isabel Rubio-Aliaga ${ }^{3}$, L Katie Crosley², Susan J Duthie², Claus Mayer ${ }^{4}$, Graham Horgan ${ }^{4}$, Abigael C Polley ${ }^{5}$, Carolin Heim ${ }^{3}$, Susan LM Coort ${ }^{6}$, Chris T Evelo ${ }^{6}$, Francis Mulholland ${ }^{5}$, lan T Johnson ${ }^{5}$, Ruan M Elliott ${ }^{5}$, Hannelore Daniel ${ }^{3}$ and Edwin CM Mariman ${ }^{1 *}$

\begin{abstract}
Background: Proteomic technologies applied for profiling human biofluids and blood cells are considered to reveal new biomarkers of exposure or provide insights into novel mechanisms of adaptation.

Methods: Both a non-targeted (classical 2D-electrophoresis combined with mass spectrometry) as well as a targeted proteomic approach (multiplex immunoassay) were applied to investigate how fasting for $36 \mathrm{~h}$, as compared to $12 \mathrm{~h}$, affects the proteome of platelets, peripheral blood mononuclear cells (PBMC), plasma, urine and saliva collected from ten healthy volunteers.

Results: Between-subject variability was highest in the plasma proteome and lowest in the PBMC proteome. Random Forests analysis performed on the entire dataset revealed that changes in the level of the RhoGDI2 protein in PBMC and plasma ApoA4 levels were the two most obvious biomarkers of an extended fasting. Random Forests (RF) analysis of the multiplex immunoassay data revealed leptin and MMP-3 as biomarkers for extended fasting. However, high between-subject variability may have masked the extended fasting effects in the proteome of the biofluids and blood cells.

Conclusions: Identification of significantly changed proteins in biofluids and blood cells using a non-targeted approach, together with the outcome of targeted analysis revealed both known and novel markers for a $36 \mathrm{~h}$ fasting period, including the cellular proteins RhoGDI2 and CLIC1, and plasma proteins ApoA4, leptin and MMP-3. The PBMC proteome exhibited the lowest between-subject variability and therefore these cells appear to represent the best biosamples for biomarker discovery in human nutrigenomics.
\end{abstract}

\section{Background}

There is an emerging demand on biomarker discovery especially in the field of nutrition with respect to weight regulation and obesity [1]. Proteomic technologies are increasingly being applied in nutrition research to reveal biomarkers that can help to demonstrate effectiveness of certain diets. Furthermore, these technologies also aid the discovery of mechanisms whereby dietary regimens

\footnotetext{
* Correspondence: e.mariman@maastrichtuniversity.nl

'Department of Human Biology, NUTRIM, Maastricht University, Maastricht, the Netherlands

Full list of author information is available at the end of the article
}

influence health $[2,3]$. Caloric restriction or fasting is a popular and efficient way to reduce weight $[4,5]$. In this study we investigated how an extended fasting period from $12 \mathrm{~h}$ to $36 \mathrm{~h}$ is reflected in the proteome of several body fluids and some of their cellular components. After $36 \mathrm{~h}$ fasting all glycogen resources are used [6]. The proteomic applications used were classical 2D-electrophoresis combined with mass spectrometry for protein identification, as a non-targeted approach, and a multiplex-based immunoassay, as a targeted approach. Our aim was to see which type of application best detected responses to a fasting period of $36 \mathrm{~h}$ and which body

\section{() Biomed Central}


fluid or blood cells would be most appropriate to reflect such responses.

This human trial was part of the European Nutrigenomics Organization (NuGO) Proof of Principal Study (PPS) in which various omic techniques were applied [7], including transcriptomics, proteomics and metabolomics [8]. This component of the PPS was designed to evaluate experimental and biological variation on the individual level in nutrigenomic experiments as a basis for future personalized nutrition concepts [9].

\section{Methods}

\section{Study design and sample preparation}

The goals and design of the human PPS have been described recently [7]. Ethical permission for the study was obtained from the North of Scotland Research Ethics Services prior to the start of the study, and all volunteers gave informed consent. Ten healthy volunteers ( 3 males and 7 females) were enrolled at the Rowett Institute of Nutrition and Health, University of Aberdeen. The BMI of volunteers ranged from 18.5 to $39.7 \mathrm{~kg} / \mathrm{m} 2$ and the age of the volunteers ranged from 25 to 56 years. The volunteers were asked to come to the Human Nutrition Unit once a week on different days each week during a four week period after an overnight fast to provide a blood sample (for the isolation of plasma, PBMC and platelets) and a saliva and $24 \mathrm{~h}$ urine sample. After the fourth sampling day, volunteers were fasted for an additional $24 \mathrm{~h}$ (total of $36 \mathrm{~h}$ ) followed by sample collection (Figure 1). Blood samples were collected into vacutainers containing potassium EDTA anticoagulant. The isolation of platelets, PBMC, plasma, saliva and urine were performed as described by
Crosley et al. [10]. Protein concentrations of platelets, PBMC, saliva and urine were assessed by the RC/DC assay (BioRad) according to the manufacturer's instructions. The protein contents of plasma samples were determined using 2-D Quant kits (GE Healthcare) according to the manufacturer's instructions. The samples were immediately aliquoted, snap frozen in liquid nitrogen, stored at $-80^{\circ} \mathrm{C}$ and shipped to the different laboratories for analysis.

\section{Analysis of plasma proteins by multiplex immunoassay}

The concentrations of 89 proteins were measured by Rules-Based Medicine (RBM) in all plasma samples by a multiplex immunoassay (HumanMAP Version 1.6, Rules-Based Medicine, Inc., Austin TX, USA).

\section{D-electrophoresis}

The platelets and saliva were analyzed in laboratory 1 , PBMC and urine in laboratory 2 and depleted plasma in laboratory 3. Each of the three laboratories ran one gel per sampling time point, the 4 overnight fasting time points were considered as replicates. 2D-electrophoresis was performed as described previously [11]. Briefly, for the blood related samples $200-250 \mu$ g protein was loaded onto a $24 \mathrm{~cm} \mathrm{4-7} \mathrm{linear} \mathrm{IPG} \mathrm{strip} \mathrm{for} \mathrm{separation}$ in the first dimension. Prior to IEF the plasma samples were depleted of Albumin and IgG using the Albumin and IgG Removal Kit (GE Healthcare) according to the manufacturer's instructions. The second dimension separation was on a standard 12\% SDS-PAGE for platelets and PBMC, the second dimension of the depleted plasma was separated on a $1 \mathrm{~mm}$ thick $10 \%$ Duracryl gel [11]. For the saliva samples, $25 \mu \mathrm{g}$ protein was

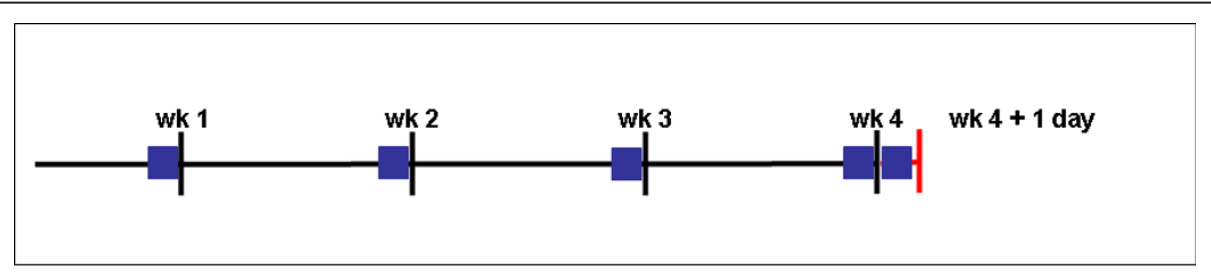

$n=10$ subjects

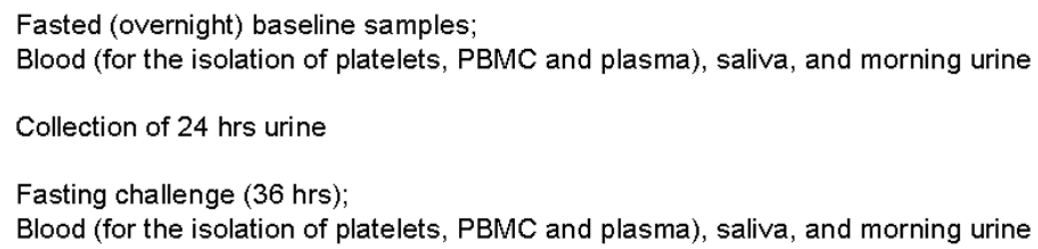

Figure 1 Schematic representation of the study design. 
loaded onto an $11 \mathrm{~cm}$ 4-7 linear IPG strip for separation in the first dimension. The second dimension separation was carried out on a $12 \%$ SDS-PAGE. For the urine samples $300 \mu \mathrm{g}$ protein was loaded onto an $18 \mathrm{~cm} \mathrm{pH}$ 4-7 linear IPG strip. The gels with urine proteins were stained with Coomassie. Gels with proteins obtained from other biofluids and blood cells were stained with Flamingo fluorescent stain (Biorad) according to the manufacturer's instructions. Spots were identified and analyzed using the PDQuest v8.0 software (Biorad) for the platelets and saliva; Delta2D v3.6 (Decodon) for the PBMC and urine and Progenesis SameSpots v3.1 (Nonlinear Dynamics) for depleted plasma. Background subtraction and normalization were automatically carried out by the software programs.

\section{Protein identification}

The selected protein spots were excised from the 2D gels and processed for protein identification in the same laboratory where the gels were run. Generation of tryptic digest from the protein by in-gel digestion was performed as described previously $[11,12]$.

\section{MALDI-TOF/TOF mass spectrometry}

For MS/MS analysis of the spots from platelets and saliva (laboratory 1), $1.0 \mu \mathrm{l}$ of the peptide mixture and $1.0 \mu \mathrm{l}$ matrix solution $(2.5 \mathrm{mg} / \mathrm{ml} \mathrm{CHCA}$ in $50 \%$ acetonitrile/0.1\% trifluoroacetic acid; TFA) were spotted on a 384-well MALDI target plate. Data were collected with a MALDI-TOF/TOF mass spectrometer (4800 MALDITOF/TOF Proteomics Analyzer, Applied Biosystems). A default calibration was applied using a six-component peptide standard spotted onto 13 different positions of the MALDI target plate for MS, and Glu-Fibrinopeptide B (m/z 1570,68) fragmentation for MS/MS. Typically, 1000 shots were combined for obtaining MS spectra and for MS/MS spectra 2000 shots were combined. The GPS Explorer v3.6 software (Applied Biosystems) was employed to generate peak lists and automated MASCOT searches against the Swiss-Prot protein database (Swiss-Prot release 56.5; 402482 sequences) for protein identification. One miss-cleavage was tolerated; carbamidomethylation was set as a fixed modification and oxidation of methionine as an optional modification. The protein charge was set at $1+$. The precursor tolerance was set to $100 \mathrm{ppm}$ and the MS/MS tolerance was set at $0.2 \mathrm{Da}$. No restrictions were made on the protein mass. Protein hits with a MASCOT protein score greater than $56(\mathrm{p}<0.05)$ and a GPS Explorer protein score confidence index $>95 \%$ were validated as confirmed identifications [13].

The identity of the plasma, PBMC and urine spots (laboratory 2 and 3) was determined by peptide fingerprinting using an Ultraflex MALDI-TOF/TOF mass spectrometer (Bruker Daltonics Ltd.). A $200 \mathrm{~Hz}$ nitrogen laser was used to desorb/ionize the matrix/analyte material, and ions were detected in positive ion reflectron mode. All spectra were acquired automatically using the Bruker fuzzy logic algorithm (FlexControl 3.0, Bruker) and a Biotools 3.0 search routine. The resulting mass data was interrogated using an offline version of the MASCOT search engine (Matrix Science) using the SPtrEMBL database with the following search criteria: allowance of 0 or 1 missed cleavages; peptide mass tolerance of $50 \mathrm{ppm}$; trypsin as digestion enzyme; carbamidomethyl modification of cysteine; methionine oxidation as partial modification; and charged state as $\mathrm{MH}+[14]$.

\section{Statistical analysis}

Exploratory analysis of the data indicated that a logtransformation was advisable for most data sets. For reasons of consistency all data sets were analyzed on a $\log _{2}$-scale and back transformed to report fold changes. For the extended fasting effect analysis, a linear model including time point (5 levels) and subject (10 levels) as factors was fitted to the 50 data points for each variable. The extended fasting effect was then defined as a contrast that compared time point 5 (36 hours fasting) with the average of the 4 baseline measurements (overnight fasting). The 4 baseline time points were used to determine the between-subject effect, again using a linear model with subject as the only factor. P-values were adjusted for multiple testing within each data set by using the Benjamini-Hochberg method.

Spots were selected for protein identification if their adjusted $\mathrm{p}$-value fell below 0.2 allowing a false discovery rate (FDR) of $20 \%$. Linear model analysis and P-value adjustment were performed using the $\mathrm{R}$ package v2.10.1. In order not to miss any interesting spots we also performed additional analyses on the original scale and also selected proteins with an adjusted P below 0.2 on this scale. In this way we identified 10 proteins from the 2D-electrophoresis and 39 proteins for the multiplex immunoassay which were significantly changed upon the extended fasting. The data were imported into GeneMaths v2.11 for discriminant principal component analysis and cluster analysis with Pearson correlation. We used the R package v2.10.1 for random forests (RF) analysis, RF package 4.5-34 [15]. RF analysis was applied to normalized data. The number of trees was set to 500 and the number of variables randomly sampled as candidates at each split was set to 9. Ten cycles were calculated and averaged. These average mean decreased Gini results were plotted. The Gini importance indicates the importance of the variable in the classification. Cytoscape v2.7 with the MiMI plug-in 3.0.1 was used to create network associations. All proteomic data $(2 \mathrm{D}$ and RBM) where used for creating the network. The protein-protein interaction network was created using all 
Table 1 Number of protein spots/proteins that change during fasting challenge

\begin{tabular}{lccc}
\hline & $\begin{array}{c}\text { Fasting } \\
\text { effect }\end{array}$ & $\begin{array}{c}\text { Subject } \\
\text { effect }\end{array}$ & $\begin{array}{c}\text { Total detected spots/ } \\
\text { proteins }\end{array}$ \\
\hline $\begin{array}{l}\text { Non-targeted } \\
\text { approach }\end{array}$ & 13 & 703 & 1018 \\
$\begin{array}{l}\text { Plasma } \\
\text { proteomics }\end{array}$ & 83 & 4 & 910 \\
$\begin{array}{l}\text { PBMC proteomics } \\
\text { Platelet } \\
\text { proteomics }\end{array}$ & 0 & 2 & 604 \\
$\begin{array}{l}\text { Saliva proteomics } \\
\text { Urine proteomics }\end{array}$ & 1 & 69 & 208 \\
$\begin{array}{l}\text { Targeted } \\
\text { approach }\end{array}$ & 3 & 58 & 142 \\
$\begin{array}{l}\text { Rules Based } \\
\text { Medicine }\end{array}$ & 39 & 78 & 89 \\
\hline
\end{tabular}

A fasting and a between-subject effect was observed.

available databases present in MiMI, among which are IntAct, BIND and KEGG [16].

\section{Results}

In the proteome of most biofluids and blood cells an effect of an extended fasting period from $12 \mathrm{~h}$ to $36 \mathrm{~h}$ could be observed. However, the number of proteins that changed as a result of the extended fasting was relatively small compared to the large number of proteins that differed significantly between subjects. Of the 2971 detected spots/proteins in all data sets, 153 spots/ proteins were changed due to extended fasting (5.1\%), whereas 914 mostly other spots/proteins exhibited significant between-subject differences (30.8\%). In plasma, for example, extended fasting resulted in a significant alteration of only $1.3 \%$ of the protein spots, whereas $69.1 \%$ of the spots differed significantly between subjects, when using 2D-electrophoresis. Blood cells, on the other hand, showed a remarkably lower number of proteins that exhibited significant between-subject differences $(0.3 \%$ and $0.4 \%$ of the proteins in platelets and $\mathrm{PBMC}$, respectively). Moreover, $\mathrm{PBMC}$ showed the highest number of proteins that changed significantly when volunteers extended fasting from $12 \mathrm{~h}$ to $36 \mathrm{~h}$ (9.1\%). With the targeted approach using RBM, 39 plasma proteins $(43.8 \%)$ changed significantly due to extended fasting, and 78 proteins $(87.6 \%)$ differed significantly between subjects (Table 1 ).

Using the 2D-electrophoresis approach we identified proteins from spots with a relatively highly significant adjusted p-value as a result of extended fasting: 5 spots in plasma, 2 spots in PBMC, 1 spot in saliva and 2 spots in urine (see Table 2 and Figure 2). Using the targeted approach, we were able to identify 39 proteins that changed significantly upon $36 \mathrm{~h}$ fasting compared to overnight fasting (Table 3). The chloride intracellular channel protein 1 (CLIC1) in PBMC exhibited a 5.3-fold increase upon the fasting challenge. This was the most pronounced change amongst all proteins (Table 2). C reactive protein (CRP) was detected as increasing in both the plasma $2 \mathrm{D}$ proteome and the RBM plasma data set induced by extended fasting (Table 2 and 3).

Principal component analysis applied to the multiplex immunoassay (RBM) data set revealed that each of the subjects could be identified based on levels of 89 plasma proteins (Figure 3). It appears that such data can be used to provide a metabolic fingerprint of the individual volunteers participating in this intervention study. However, this demonstrates that the between-subject effects are larger than that of the fasting effect.

RF analysis applied to the full data set from non-targeted and targeted proteomics applications, revealed

Table 2 Protein identifications by MS/MS analysis of biofluid and blood cell proteins which were significantly increased or decreased upon extended fasting (36 h), as compared with overnight fasting (12 h)

\begin{tabular}{|c|c|c|c|c|c|c|c|c|c|}
\hline $\begin{array}{l}\text { Sample } \\
\text { type }\end{array}$ & Spot & $\begin{array}{c}\text { Accession } \\
\#\end{array}$ & Protein identification & $\begin{array}{l}\text { Fold- } \\
\text { change }\end{array}$ & p-value & $\begin{array}{c}\text { Adjusted } \\
\text { p-value }\end{array}$ & $\begin{array}{l}\text { Mascot } \\
\text { score }\end{array}$ & $\begin{array}{l}\text { Sequence } \\
\text { Coverage } \%\end{array}$ & $\begin{array}{l}\text { Matched } \\
\text { peptides }\end{array}$ \\
\hline \multirow[t]{5}{*}{ Plasma } & 1 & P06727 & Apolipoprotein A-IV (ApoA4) & -1.80 & $<0.001$ & $<0.001$ & 426 & 69 & 34 \\
\hline & 2 & P00738 & Haptoglobin B chain & -1.15 & $<0.001$ & 0.009 & 87 & 32 & 8 \\
\hline & 3 & P00738 & Haptoglobin B chain fragment & -1.14 & $<0.001$ & 0.006 & 139 & 33 & 17 \\
\hline & 4 & P36955 & $\begin{array}{l}\text { Pigment epithelium-derived } \\
\text { factor }\end{array}$ & -1.09 & $<0.001$ & 0.061 & 113 & 35 & 16 \\
\hline & 5 & P02741 & C reactive protein $(C R P)$ & 1.42 & $<0.001$ & 0.061 & 74 & 17 & 6 \\
\hline \multirow[t]{2}{*}{ PBMC } & 6 & P52566 & $\begin{array}{l}\text { Rho GDP-dissociation inhibitor } 2 \\
\text { (RhoGDI2) }\end{array}$ & -2.78 & $<0.001$ & $<0.001$ & 63 & 23 & 4 \\
\hline & 7 & O00299 & $\begin{array}{l}\text { Chloride intracellular channel } \\
\text { protein } 1 \text { (CLIC1) }\end{array}$ & 5.30 & $<0.001$ & $<0.001$ & 73 & 23 & 4 \\
\hline Saliva & 8 & P01833 & $\begin{array}{l}\text { Polymeric-immunoglobulin } \\
\text { receptor (PIGR) }\end{array}$ & -3.16 & $<0.001$ & 0.030 & 161 & 15 & 10 \\
\hline \multirow[t]{2}{*}{ Urine } & 9 & P02768 & Serum albumin precursor & 1.83 & 0.004 & 0.185 & 162 & 45 & 22 \\
\hline & 10 & P02768 & Serum albumin precursor & 2.02 & 0.001 & 0.056 & 152 & 32 & 16 \\
\hline
\end{tabular}



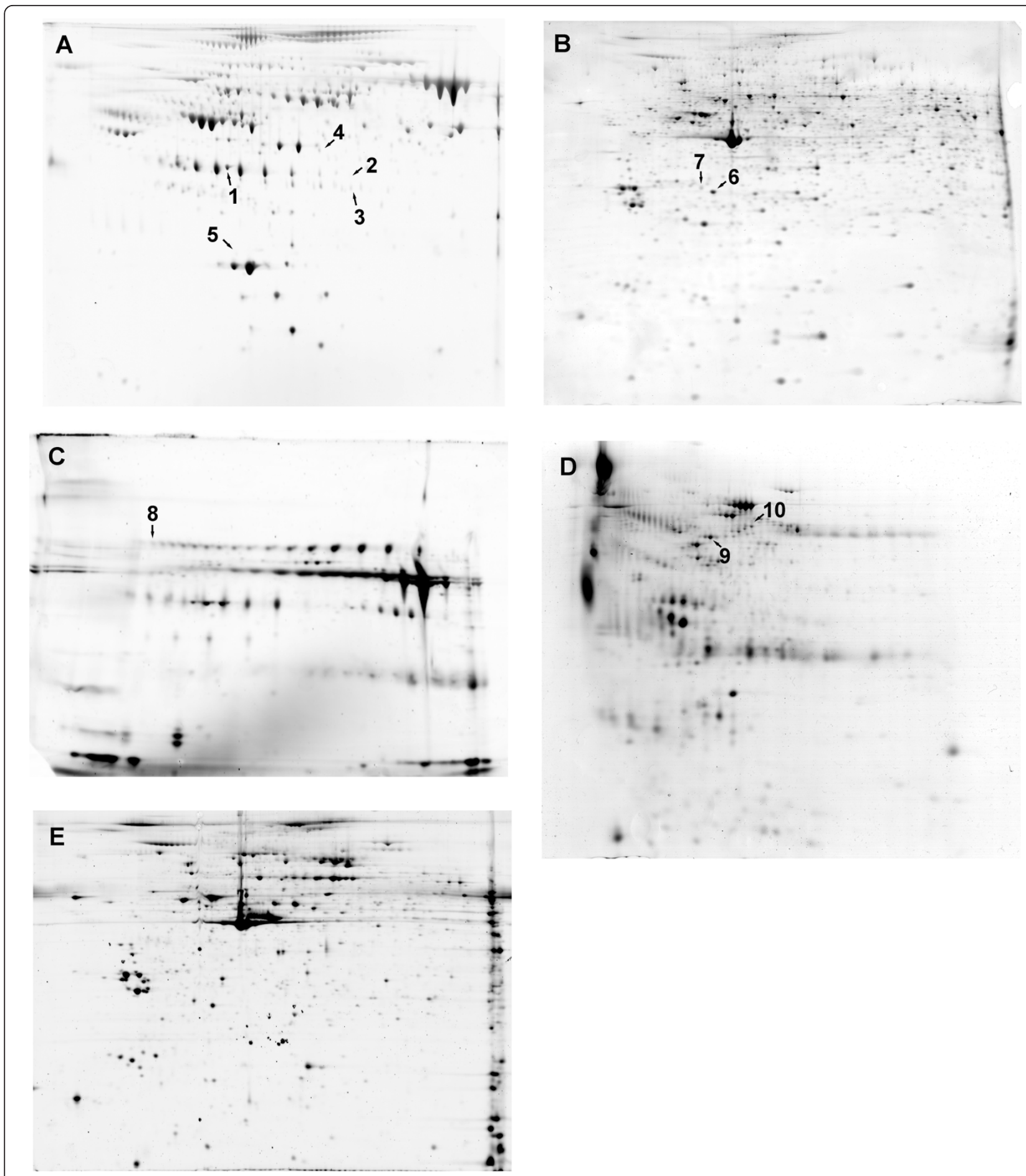

Figure 2 Identified proteins marked on 2D gels representing plasma (A), PBMC (B), saliva (C), urine (D) and platelets (E). The numbers refer to those used in Table 2 .

that the Rho GDP-dissociation inhibitor 2 (RhoGDI2) in PBMC and the plasma Apolipoprotein A-IV (ApoA4) appeared the most significant biomarkers associated with extended fasting (Figure 4a). RF analysis of the targeted proteomics data set revealed leptin and matrix metalloproteinase-3 (MMP-3) as biomarkers of extended fasting (Figure 4b).

Cluster analysis with Pearson correlations between the fold-change in RBM plasma proteins after extended fasting versus overnight fasting is shown in Figure 5. Leptin 
Table 3 Plasma proteins of which absolute levels significantly changed due to extended fasting (36 h) compared with overnight fasting (12 h), as assessed using the multiplex immunoassay (RBM)

\begin{tabular}{|c|c|c|c|c|}
\hline Protein & Accession \# & Fold-change & p-value & Adjusted $\mathrm{p}$-value \\
\hline$\overline{\text { IGF-1 }}$ & P01343 & -2.72 & $<0.001$ & $<0.001$ \\
\hline Leptin & P41159 & -2.59 & $<0.001$ & $<0.001$ \\
\hline Erythropoietin & P01588 & -1.56 & 0.080 & 0.187 \\
\hline $\lg E$ & n.a. & -1.54 & 0.002 & 0.013 \\
\hline IL-8 & P10145 & -1.51 & $<0.001$ & 0.001 \\
\hline MMP-3 & P08254 & -1.48 & $<0.001$ & $<0.001$ \\
\hline Thyroid Stimulating Hormone & P01222 & -1.47 & $<0.001$ & $<0.001$ \\
\hline Insulin & P01308 & -1.29 & $<0.001$ & 0.001 \\
\hline Carcinoembryonic Antigen & P06731 & -1.29 & 0.037 & 0.116 \\
\hline IL-1 beta & P01584 & -1.19 & $<0.001$ & $<0.001$ \\
\hline PAl-1 & P05121 & -1.19 & 0.002 & 0.013 \\
\hline Apolipoprotein A-1 (ApoA1) & P02647 & -1.18 & 0.006 & 0.025 \\
\hline MCP-1 & P13500 & -1.17 & $<0.001$ & 0.001 \\
\hline Eotaxin & P51671 & -1.16 & 0.001 & 0.005 \\
\hline VEGF & P15692 & -1.14 & $<0.001$ & $<0.001$ \\
\hline IL-16 & Q14005 & -1.13 & $<0.001$ & 0.002 \\
\hline EGF & P01133 & -1.12 & 0.085 & 0.190 \\
\hline IL-18 & Q14116 & -1.12 & 0.013 & 0.048 \\
\hline Alpha-Fetoprotein & P02771 & -1.12 & $<0.001$ & $<0.001$ \\
\hline Fatty Acid Binding Protein & P05413 & -1.07 & 0.006 & 0.025 \\
\hline $\lg A$ & n.a. & -1.07 & 0.043 & 0.116 \\
\hline Factor VII (F7) & P08709 & -1.06 & 0.061 & 0.157 \\
\hline Creatine Kinase-MB & P06732 & -1.04 & 0.075 & 0.181 \\
\hline IL-10 & P22301 & -1.04 & 0.041 & 0.116 \\
\hline Glutathione S-Transferase & P09211 & -1.04 & 0.010 & 0.041 \\
\hline Tissue Factor (TF) & P13726 & -1.03 & 0.004 & 0.019 \\
\hline Prostatic Acid Phosphatase & P15309 & -1.03 & 0.018 & 0.067 \\
\hline Alpha-2 Macroglobulin (A2M) & P01023 & 1.02 & 0.021 & 0.072 \\
\hline Complement 3 & P01024 & 1.02 & 0.028 & 0.092 \\
\hline TIMP-1 & P01033 & 1.02 & 0.005 & 0.025 \\
\hline IL-12p70 & P29459 & 1.03 & 0.038 & 0.116 \\
\hline VCAM-1 & P19320 & 1.05 & 0.011 & 0.044 \\
\hline Serum Amyloid P (SAP) & P02743 & 1.07 & 0.072 & 0.179 \\
\hline Lipoprotein (a) & P08519 & 1.09 & 0.041 & 0.116 \\
\hline MIP-1beta & P13236 & 1.09 & 0.048 & 0.127 \\
\hline TNF-alpha & P01375 & 1.10 & 0.042 & 0.116 \\
\hline EN-RAGE & P80511 & 1.17 & 0.085 & 0.190 \\
\hline Ferritin & P02794 & 1.27 & $<0.001$ & 0.001 \\
\hline C Reactive Protein (CRP) & P02741 & 1.55 & $<0.001$ & 0.002 \\
\hline
\end{tabular}

n.a. = no accession \#.

and Insulin-like growth factor I (IGF-1) are correlated and closely clustered to each other. Both proteins are down-regulated after extended fasting (Table 3). CRP is correlated to changes in alpha-2-macroglobulin, serum amyloid $\mathrm{P}$ and adiponectin (Figure 5). The close association between CRP, serum amyloid P and alpha-2-macroglobulin is confirmed in the protein-protein interaction network shown in Figure 6. In addition, leptin changes appear directly linked to changes in CRP and alpha-2- macroglobulin, whereas MMP-3 appears directly linked to alterations in the tissue inhibitor of metalloproteinase-1 (TIMP-1), monocyte chemotactic protein-1 (MCP-1) and plasminogen activator inhibitor-1 (PAI-1).

\section{Discussion}

This study, using both non-targeted as well as targeted proteomic approaches applied to biofluids and blood cells to elucidate changes in their proteomes induced by 


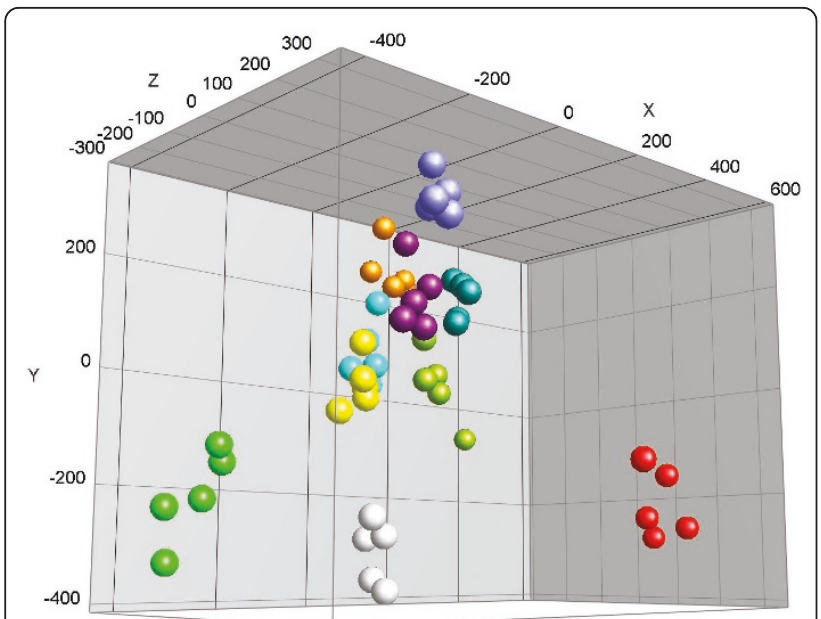

Figure 3 PCA analysis of data obtained from the multiplex immunoassay (RBM). Each color represents a different subject.

extended fasting, revealed substantial between-subject variability which may mask the true biological effect of fasting on the proteome. This suggests that any nutrigenomic experiment require a sufficient number of replicates and matched samples to identify the usually rather subtle changes that dietary maneuvers may impose. Levels of between-subject variability were higher in all biofluids samples as compared to the cellular proteomes. In this study, PBMC exhibited the largest number of significant changes in protein levels following the extended fast. RF analysis on the entire data set revealed that in PBMC the RhoGDI2 and plasma ApoA4 proteins were the most significant biomarkers for extended fasting. RF analysis of the multiplex immunoassay data set revealed leptin and MMP-3 as potential biomarkers for extended fasting.

It should be noted that the between-subject variation may in part be due to the heterogeneous composition of our study cohort with regard to various parameters, including gender and BMI. Consequently, this type of variability can be reduced by selecting a more homogeneous study population. We observed markedly less inter-individual difference in the PBMC proteome than we observed previously in the PBMC transcriptome of PBMC from human volunteers who were participating in a study with a similar baseline design [17]. In our study $0.4 \%$ of the PBMC proteins detected differed significantly between individuals compared with $39 \%$ of PBMC transcripts [17].

Most interesting biomarkers that are involved in metabolic pathways, as well as those related to inflammation and oxidative stress, are present only in very low concentrations in biosamples. In these cases, their low abundance prevents detection by classical proteomic techniques such as 2D-electrophoresis [18]. Multiplex immunoassays are therefore an interesting alternative because they are more sensitive compared to $2 \mathrm{D}$-electrophoresis [19]. Indeed, a wide range of plasma protein changes caused by extended fasting were detected using the targeted multiplex immunoassay method. However, a big advantage of $2 \mathrm{D}$-electrophoresis is that it can visualize isoforms and possible protein modifications, whereas with an antibody-based approach this depends on the availability of isoform-specific antibodies.

CLIC1 in PBMC was the protein that exhibited the largest fold-change as a result of the extended fasting. In general, chloride channels play important roles in the regulation of cellular excitability, transepithelial transport, cell volume regulation, and acidification of intracellular organelles [20]. CLIC1 is responsible for stabilization of the membrane potential, which could be influenced by the nutrient status in PBMC. Moreover CLIC1 seems to be associated with cellular stress response mechanisms and starvation may be interpreted as a metabolic stress condition [21].

Besides CLIC1, levels of RhoGDI2 and ApoA4 were the best indicators of the extended fasting state based on analysis of all the proteomic data. Insulin has the ability to relocate RhoGDI2 to the membrane [22]. Since plasma glucose and insulin levels are low during fasting, the relative amount of RhoGDI2 in the cytosol of PBMC might be predicted to increase during extended fasting. Since by 2D preferentially cytosolic proteins are detected, RhoGDI2 is expected to rise in spot intensity. However, a decrease was noticed in our experiment indicating that cytosolic RhoGDI2 concentration is influenced by other factors like posttranslational modification or turn-over rate.

ApoA4 is a major component of chylomicrons and is synthesized by the small intestine. It is proposed to represent a circulating satiety signal [23] and after fasting, therefore, may decrease its levels [24].

IGF-1, leptin and CRP were the proteins with the biggest negative and positive fold change upon the fasting challenge in the RBM data. Circulating IGF-1 levels are associated with dietary protein intake $[25,26]$. This could explain why after an extended fast without protein intake, IGF-1 is decreased [27]. The decrease of leptin is as expected because it is known to be a positive marker for fasting or weight loss [28-30]. Chan et al. [31] have shown that leptin and IGF-1 levels decrease after a $72 \mathrm{~h}$ fasting. Our correlation analysis clustered IGF-1 and leptin suggesting that adipose tissue, as the main source of leptin, and liver, as the origin of circulating IGF-1, undergo metabolic adaptation via a closely linked mechanism. CRP is an acute phase protein and its elevation after this short term fasting might therefore be 
A

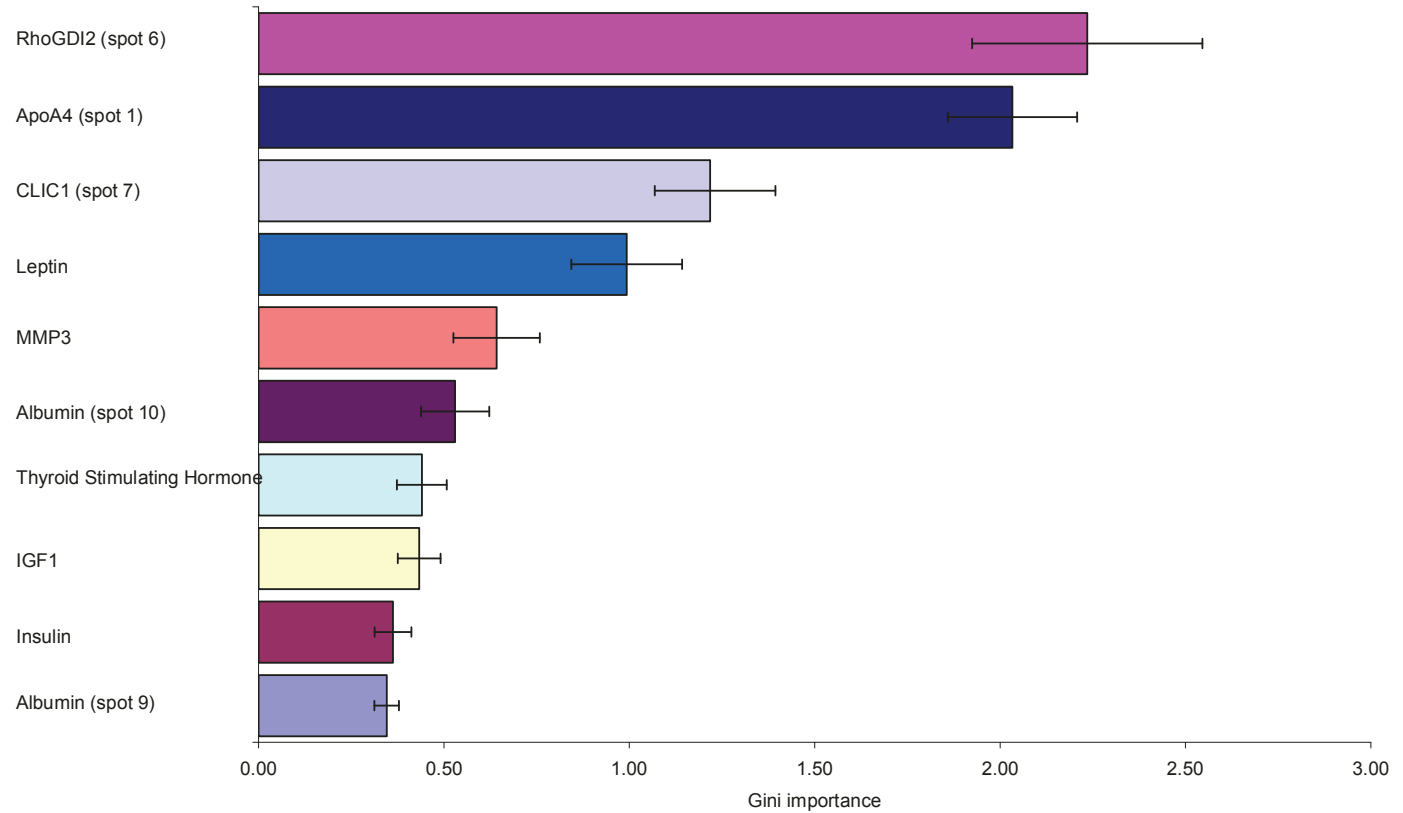

B

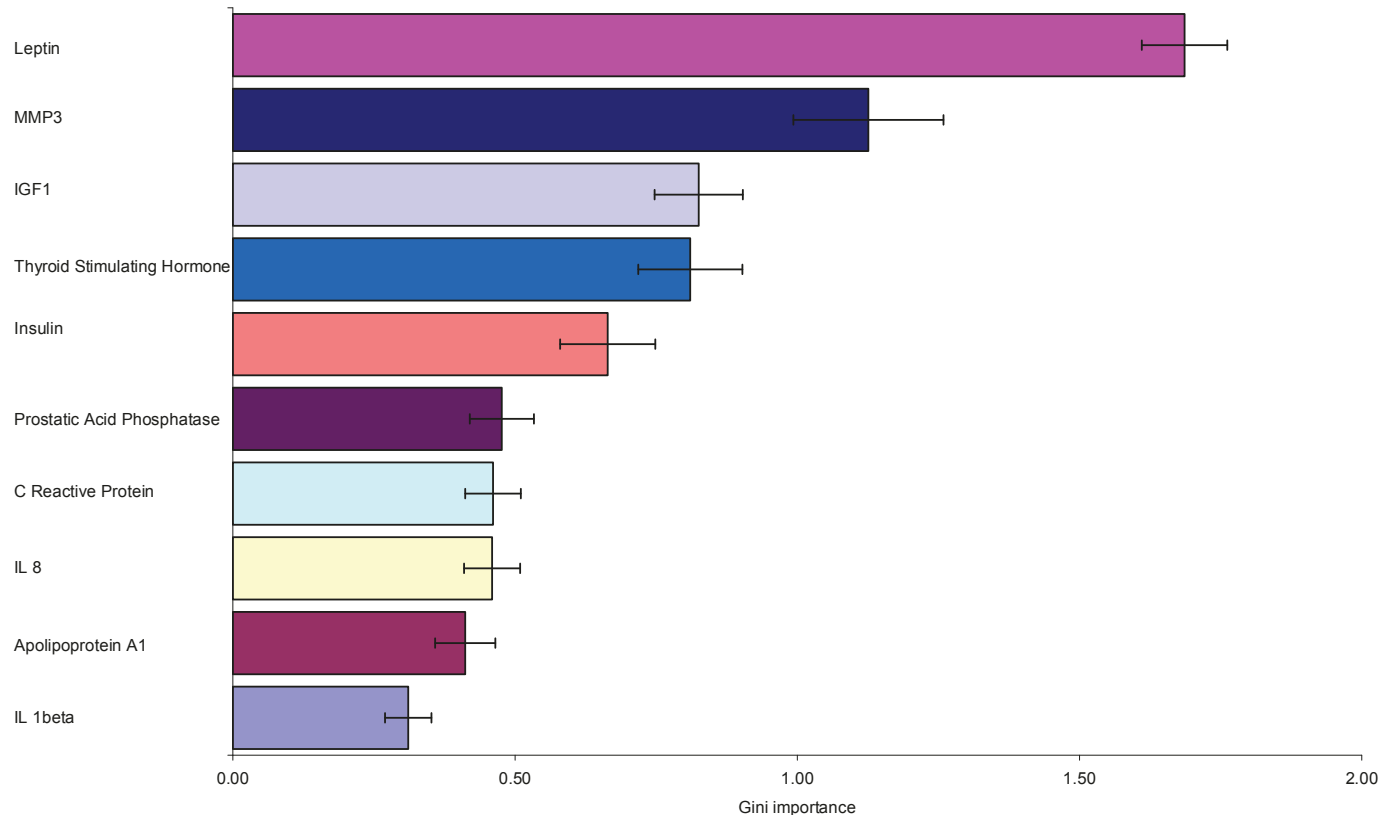

Figure 4 Biomarkers of extended fasting effect calculated by Random Forrest analysis. Panel A: results obtained from analysis of all proteomic data ( $2 \mathrm{D}$ and RBM). Panel B: results obtained from targeted proteomic analysis using multiplex immunoassay (RBM). The spot numbers between brackets refer to those used in Table 2. Proteins without numbers between brackets refer to those used in Table 3 . 


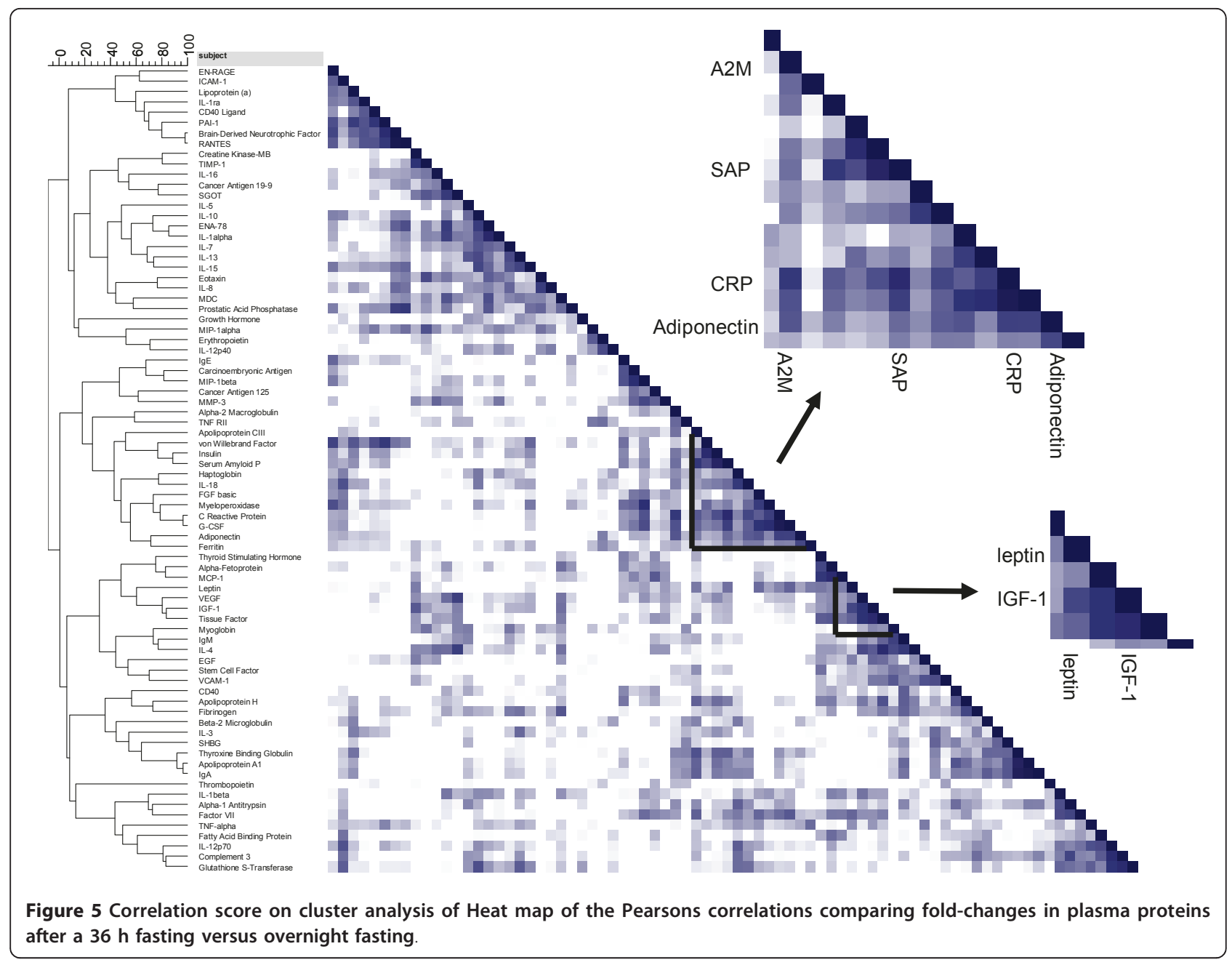

expected, although after long term fasting or caloric restriction CRP is usually down-regulated [32]. RF analysis applied to the RBM data revealed leptin and MMP-3 as the most obvious biomarkers for a fasting challenge. No direct interaction between leptin and MMP-3 has been reported so far. A possible mechanism could be the inverse correlation between leptin and adiponectin levels $[19,33]$ since the leptin/adiponectin ration changes during extended fasting. Adiponectin by itself has the ability to increase TIMP1, which is able to inhibit the activity of MMPs [34,35]. However, adiponectin plasma levels did not change significantly $(\mathrm{p}=$ 0.45) upon the extended fasting.

Most interestingly, the correlation analysis clustered CRP closely together with adiponectin, serum amyloid $\mathrm{P}$ and alpha-2-macroglobulin. Except for adiponectin, a networking interaction analysis using MiMI, places those proteins together with leptin and RhoGDI2. An interaction between leptin and CRP, which are positively correlated in normal weight, overweight and obese subjects [36], was described by Chen et al [37]. Alpha-2microglobulin is described as a leptin binding protein [38]. This interaction may be involved in the clearance of leptin by the alpha-2-microglobulin receptor.

Another observation from the networking analysis was an interaction between PAI-1, MMP-3, MCP1 and TIMP1. As mentioned above, TIMP1 inhibits the activity of MMPs [34,35], whereas both PAI- 1 and MCP1 are inactivated through proteolysis mediated by MMP-3 $[39,40]$. This interaction between MMP-3 and MCP-1 may be the reason that MMP-3 is ranked relatively high by the RF analysis. An inhibition or decrease of PAI-1 leads to a reduction of fat depots and adipocyte volume [41]. Several studies have shown that PAI-1 is increased in adipose tissue and plasma in obese humans and that plasma PAI-1 concentrations decrease after weight loss or fasting $[42,43]$, which suggests a role for this proteinase inhibitor in the development and maintenance of obesity. Jensen et al. [44] reported that a low glycemic index diet in overweight adults could be beneficial in 


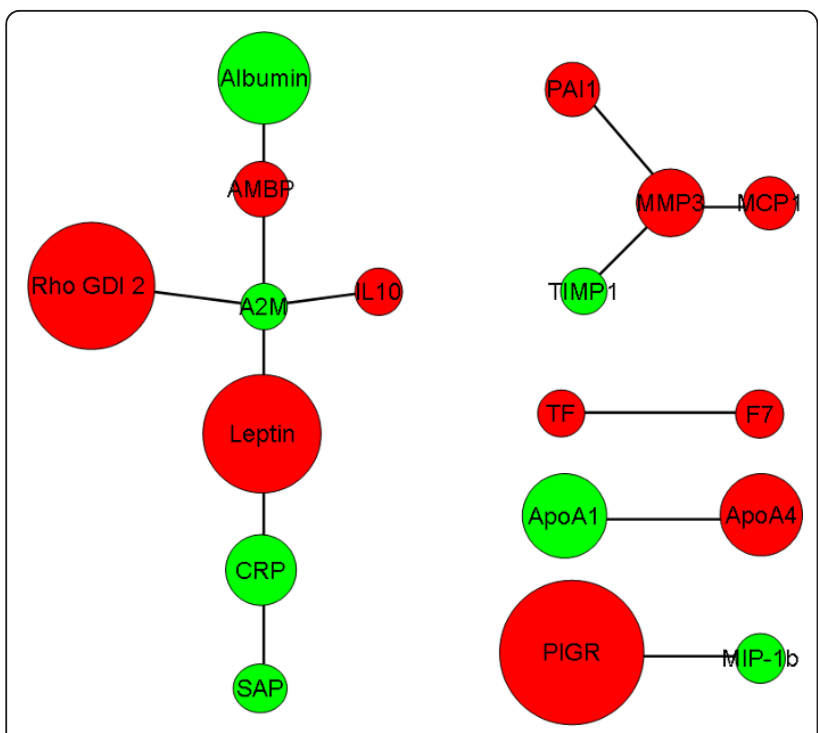

Figure 6 Protein-protein interaction networking based on the outcome of the total dataset. Red represents a decrease and green an increase in protein levels. The size of the circle represents the fold change levels. The short protein names shown in the network refer to Table 2 and 3. Alpha-1-microglobulin (AMBP) was down-regulated and ApoA1 was up-regulated in urine, but not significantly (data not shown).

regulating fasting concentrations of the cardiovascular disease risk factor PAI-1 showing that PAI-1 concentrations are sensitive to the nutritional status. PAI-1, TIMPs and MMPs play a role in extracellular matrix remodeling $[41,45,46]$. Interestingly, a correlation has been described between CRP and PAI-1 [47,48], linking both interaction networks.

\section{Conclusions}

Both non-targeted and targeted proteomic analysis on a range of human body fluid samples and selected blood cells examining the effect of an extended fasting revealed that there is a considerable between-subject effect with the lowest variability in the PBMC proteome. These cells may therefore be considered as a prime sample source in further nutrigenomic studies when proteomic technologies are applied for biomarker discovery. The antibody based analysis is superior when plasma proteins are analyzed and reveals a distinct metabolic fingerprint that identifies the individuals. The protein panel that characterizes extended fasting by the most significant changes comprises known entities such as leptin, ApoA4 and IGF-1, but also a variety of novel markers including RhoGDI2, CLIC1 and MMP-3. These candidate biomarkers could be of interest in future nutrition studies.

\section{Acknowledgements}

This research was supported by NuGO (The European Nutrigenomics Organization: linking genomics, nutrition and health research; CT-2004505944). The Rowett Institute of Nutrition and Health is funded by the
Scottish Government Rural and Environment Research and Analysis Directorate (RERAD). The Institute of Food Research is funded by the Biotechnology and Biological Sciences Research Council (BBSRC). We also thank Barbara Gelhaus for her excellent analysis of the PBMC and urine samples. We thank Ping Wang for the help of the random forests analysis.

\section{Author details}

'Department of Human Biology, NUTRIM, Maastricht University, Maastricht, the Netherlands. ${ }^{2}$ Rowett Institute of Nutrition and Health, University of Aberdeen, Aberdeen, UK. ${ }^{3}$ Molecular Nutrition Unit, ZIEL - Research Center for Nutrition and Food Sciences, Technische Universität München, FreisingWeihenstephan, Germany. ${ }^{4}$ Biomathematics and Statistics Scotland,

Aberdeen, UK. ${ }^{5}$ Institute of Food Research, Norwich Research Park, Norwich, UK. ${ }^{6}$ Department of Bioinformatics - BiGCaT, NUTRIM, Maastricht University, Maastricht, the Netherlands.

\section{Authors' contributions}

FB designed and performed the experiments, analyzed the data and wrote the manuscript. BR conceived, designed and coordinated the study, analyzed the data. IRA designed the study, performed the experiments and analyzed the data. KC designed the study and collected the samples. SD designed and coordinated the study. CM collected the raw data and performed the statistic analysis. GH performed the statistic analysis. AP designed and performed the experiments. $\mathrm{CH}$ designed and performed the experiments. SC participated in the data analysis. CE participated in the data analysis. FM designed the study and performed the experiments. IJ designed the study and performed the experiments. RE designed and coordinated the study, performed the experiments and analyzed the data. HD designed and coordinated the study. EM designed and coordinated the study and participated in manuscript writing. All authors read and approved the final manuscript.

\section{Competing interests}

The authors declare that they have no competing interests.

Received: 26 October 2010 Accepted: 25 March 2011

Published: 25 March 2011

\section{References}

1. Kussmann M, Raymond F, Affolter M: OMICS-driven biomarker discovery in nutrition and health. Journal of biotechnology 2006, 124(4):758-787.

2. de Roos B: Nutrition proteomics and biomarker discovery. Expert review of proteomics 2009, 6(4):349-351.

3. de Roos B, McArdle HJ: Proteomics as a tool for the modelling of biological processes and biomarker development in nutrition research. The British journal of nutrition 2008, 99(Suppl 3):S66-71.

4. Johnstone AM: Fasting - the ultimate diet? Obes Rev 2007, 8(3):211-222.

5. Bahadori B, McCarty MF, Barroso-Aranda J, Gustin JC, Contreras F: A "minifast with exercise" protocol for fat loss. Medical hypotheses 2009, 73(4):619-622.

6. Cahill GF Jr: Fuel metabolism in starvation. Annual review of nutrition 2006, 26:1-22.

7. Baccini M, Bachmaier EM, Biggeri A, Boekschoten MV, Bouwman FG, Brennan L, Caesar R, Cinti S, Coort SL, Crosley K, et al: The NuGO proof of principle study package: a collaborative research effort of the European Nutrigenomics Organisation. Genes \& nutrition 2008, 3(3-4):147-151.

8. Rubio-Aliaga I, de Roos B, Duthie SJ, Crosley LK, Mayer C, Horgan G, Colquhoun IJ, Le Gall G, Huber F, Kremer W, et al: Metabolomics of prolonged fasting in humans: from physiology to individual metabotypes. Metabolomics

9. Kussmann M, Rezzi S, Daniel H: Profiling techniques in nutrition and health research. Current opinion in biotechnology 2008, 19(2):83-99.

10. Crosley LK, Duthie SJ, Polley AC, Bouwman FG, Heim C, Mulholland F, Horgan G, Johnson IT, Mariman EC, Elliott RM, et al: Variation in protein levels obtained from human blood cells and biofluids for platelet, peripheral blood mononuclear cell, plasma, urine and saliva proteomics. Genes \& nutrition 2009, 4(2):95-102.

11. de Roos B, Duthie SJ, Polley AC, Mulholland F, Bouwman FG, Heim C, Rucklidge GJ, Johnson IT, Mariman EC, Daniel H, et al: Proteomic methodological recommendations for studies involving human plasma, 
platelets, and peripheral blood mononuclear cells. Journal of proteome research 2008, 7(6):2280-2290

12. Bouwman F, Suylen D, Renes J, Mariman E: Evaluation and improving the success rate of protein identification by peptide mass fingerprinting using matrix-assisted laser desorption/ionization timeof-flight mass spectrometry. Rapid Commun Mass Spectrom 2005, 19(17):2465-2468.

13. Cranenburg EC, Vermeer C, Koos R, Boumans ML, Hackeng TM, Bouwman FG, Kwaiitaal M, Brandenburg VM, Ketteler M, Schurgers LJ: The circulating inactive form of matrix Gla Protein (UCMGP) as a biomarker for cardiovascular calcification. Journal of vascular research 2008, 45(5):427-436.

14. Fuchs D, Dirscherl B, Schroot JH, Daniel H, Wenzel U: Proteome analysis suggests that mitochondrial dysfunction in stressed endothelial cells is reversed by a soy extract and isolated isoflavones. Journal of proteome research 2007, 6(6):2132-2142.

15. Breiman L: Random forests. Machine Learning 2001, 45(1):5-32.

16. Gao J, Ade AS, Tarcea VG, Weymouth TE, Mirel BR, Jagadish HV, States DJ: Integrating and annotating the interactome using the MiMl plugin for cytoscape. Bioinformatics (Oxford, England) 2009, 25(1):137-138.

17. Eady JJ, Wortley GM, Wormstone YM, Hughes JC, Astley SB, Foxall RJ, Doleman JF, Elliott RM: Variation in gene expression profiles of peripheral blood mononuclear cells from healthy volunteers. Physiol Genomics 2005, 22(3):402-411.

18. Kenyon GL, DeMarini DM, Fuchs E, Galas DJ, Kirsch JF, Leyh TS, Moos WH, Petsko GA, Ringe D, Rubin GM, et al: Defining the mandate of proteomics in the post-genomics era: workshop report. Mol Cell Proteomics 2002, 1(10):763-780

19. Schipper HS, de Jager W, van Dijk ME, Meerding J, Zelissen PM, Adan RA, Prakken BJ, Kalkhoven E: A Multiplex Immunoassay for Human Adipokine Profiling. Clinical chemistry 2010, 56(8):1320-1328.

20. Nilius B, Droogmans G: Amazing chloride channels: an overview. Acta physiologica Scandinavica 2003, 177(2):119-147.

21. Wang P, Bouwman FG, Mariman EC: Generally detected proteins in comparative proteomics-a matter of cellular stress response? Proteomics 2009, 9(11):2955-2966.

22. Shisheva A, Buxton J, Czech MP: Differential intracellular localizations of GDP dissociation inhibitor isoforms. Insulin-dependent redistribution of GDP dissociation inhibitor-2 in 3T3-L1 adipocytes. The Journal of biological chemistry 1994, 269(39):23865-23868.

23. Tso P, Chen Q, Fujimoto K, Fukagawa K, Sakata T: Apolipoprotein A-IV: a circulating satiety signal produced by the small intestine. Obesity research 1995, 3(Suppl 5):689S-695S.

24. Bertile F, Schaeffer C, Le Maho Y, Raclot T, Van Dorsselaer A: A proteomic approach to identify differentially expressed plasma proteins between the fed and prolonged fasted states. Proteomics 2009, 9(1):148-158.

25. Hoppe C, Udam TR, Lauritzen L, Molgaard C, Juul A, Michaelsen KF: Animal protein intake, serum insulin-like growth factor $\mathrm{I}$, and growth in healthy 2.5-y-old Danish children. The American journal of clinical nutrition 2004, 80(2):447-452.

26. Hoppe C, Kristensen M, Boiesen M, Kudsk J, Fleischer Michaelsen K, Molgaard C: Short-term effects of replacing milk with cola beverages on insulin-like growth factor-I and insulin-glucose metabolism: a $10 \mathrm{~d}$ interventional study in young men. The British journal of nutrition 2009, 102(7):1047-1051.

27. Longo VD, Fontana L: Calorie restriction and cancer prevention: metabolic and molecular mechanisms. Trends in pharmacological sciences 2010, 31(2):89-98.

28. Stefan N, Fritsche A, Haring H, Stumvoll M: Acute stimulation of leptin concentrations in humans during hyperglycemic hyperinsulinemia. Influence of free fatty acids and fasting. Int J Obes Relat Metab Disord 2001, 25(1):138-142.

29. Chan JL, Mietus JE, Raciti PM, Goldberger AL, Mantzoros CS: Short-term fasting-induced autonomic activation and changes in catecholamine levels are not mediated by changes in leptin levels in healthy humans. Clinical endocrinology 2007, 66(1):49-57.

30. Ahima RS, Prabakaran D, Mantzoros C, Qu D, Lowell B, Maratos-Flier E, Flier JS: Role of leptin in the neuroendocrine response to fasting. Nature 1996, 382(6588):250-252.
31. Chan JL, Williams CJ, Raciti P, Blakeman J, Kelesidis T, Kelesidis I, Johnson ML, Thorner MO, Mantzoros CS: Leptin does not mediate shortterm fasting-induced changes in growth hormone pulsatility but increases IGF-I in leptin deficiency states. The Journal of clinical endocrinology and metabolism 2008, 93(7):2819-2827.

32. Fontana $L$, Meyer TE, Klein $S$, Holloszy JO: Long-term calorie restriction is highly effective in reducing the risk for atherosclerosis in humans. Proceedings of the National Academy of Sciences of the United States of America 2004, 101(17):6659-6663.

33. Matsubara M, Maruoka S, Katayose S: Inverse relationship between plasma adiponectin and leptin concentrations in normal-weight and obese women. European journal of endocrinology/European Federation of Endocrine Societies 2002, 147(2):173-180.

34. Chen TH, Chen L, Hsieh MS, Chang CP, Chou DT, Tsai SH: Evidence for a protective role for adiponectin in osteoarthritis. Biochimica et biophysica acta 2006, 1762(8):711-718

35. Kumada M, Kihara S, Ouchi N, Kobayashi H, Okamoto Y, Ohashi K, Maeda K, Nagaretani H, Kishida K, Maeda N, et al: Adiponectin specifically increased tissue inhibitor of metalloproteinase-1 through interleukin-10 expression in human macrophages. Circulation 2004, 109(17):2046-2049.

36. Shamsuzzaman AS, Winnicki M, Wolk R, Svatikova A, Phillips BG, Davison DE, Berger PB, Somers VK: Independent association between plasma leptin and C-reactive protein in healthy humans. Circulation 2004, 109(18):2181-2185.

37. Chen K, Li F, Li J, Cai H, Strom S, Bisello A, Kelley DE, Friedman-Einat M, Skibinski GA, McCrory MA, et al: Induction of leptin resistance through direct interaction of C-reactive protein with leptin. Nature medicine 2006, 12(4):425-432.

38. Birkenmeier G, Kampfer I, Kratzsch J, Schellenberger W: Human leptin forms complexes with alpha 2-macroglobulin which are recognized by the alpha 2-macroglobulin receptor/low density lipoprotein receptorrelated protein. European journal of endocrinology/European Federation of Endocrine Societies 1998, 139(2):224-230.

39. Lijnen HR, Arza B, Van Hoef B, Collen D, Declerck PJ: Inactivation of plasminogen activator inhibitor-1 by specific proteolysis with stromelysin-1 (MMP-3). The Journal of biological chemistry 2000, 275(48):37645-37650.

40. McQuibban GA, Gong JH, Wong JP, Wallace JL, Clark-Lewis I, Overall CM: Matrix metalloproteinase processing of monocyte chemoattractant proteins generates CC chemokine receptor antagonists with anti-inflammatory properties in vivo. Blood 2002, 100(4):1160-1167.

41. Mariman EC, Wang P: Adipocyte extracellular matrix composition, dynamics and role in obesity. Cell Mol Life Sci 2010, 67(8):1277-1292.

42. Mavri A, Alessi MC, Bastelica D, Geel-Georgelin O, Fina F, Sentocnik JT, Stegnar M, Juhan-Vague I: Subcutaneous abdominal, but not femoral fat expression of plasminogen activator inhibitor-1 (PAI-1) is related to plasma PAI-1 levels and insulin resistance and decreases after weight loss. Diabetologia 2001, 44(11):2025-2031.

43. Murakami T, Horigome H, Tanaka K, Nakata Y, Ohkawara K, Katayama Y, Matsui A: Impact of weight reduction on production of platelet-derived microparticles and fibrinolytic parameters in obesity. Thrombosis research 2007, 119(1):45-53.

44. Jensen L, Sloth B, Krog-Mikkelsen I, Flint A, Raben A, Tholstrup T, Brunner N, Astrup A: A low-glycemic-index diet reduces plasma plasminogen activator inhibitor-1 activity, but not tissue inhibitor of proteinases-1 or plasminogen activator inhibitor-1 protein, in overweight women. The American journal of clinical nutrition 2008, 87(1):97-105.

45. Baker EA, Leaper DJ: The plasminogen activator and matrix metalloproteinase systems in colorectal cancer: relationship to tumour pathology. Eur J Cancer 2003, 39(7):981-988.

46. Chavey C, Mari B, Monthouel MN, Bonnafous S, Anglard P, Van Obberghen E, Tartare-Deckert S: Matrix metalloproteinases are differentially expressed in adipose tissue during obesity and modulate adipocyte differentiation. The Journal of biological chemistry 2003, 278(14):11888-11896.

47. Kraja AT, Province MA, Arnett D, Wagenknecht L, Tang W, Hopkins PN, Djousse $L$, Borecki IB: Do inflammation and procoagulation biomarkers 
contribute to the metabolic syndrome cluster? Nutrition \& metabolism 2007, 4:28.

48. Gnacinska M, Malgorzewicz S, Guzek M, Lysiak-Szydlowska W, Sworczak K: Adipose tissue activity in relation to overweight or obesity.

Endokrynologia Polska 2010, 61(2):160-168.

Pre-publication history

The pre-publication history for this paper can be accessed here: http://www.biomedcentral.com/1755-8794/4/24/prepub

doi:10.1186/1755-8794-4-24

Cite this article as: Bouwman et al:: 2D-electrophoresis and multiplex immunoassay proteomic analysis of different body fluids and cellular components reveal known and novel markers for extended fasting. BMC Medical Genomics 2011 4:24.

Submit your next manuscript to BioMed Central and take full advantage of:

- Convenient online submission

- Thorough peer review

- No space constraints or color figure charges

- Immediate publication on acceptance

- Inclusion in PubMed, CAS, Scopus and Google Scholar

- Research which is freely available for redistribution

Submit your manuscript at www.biomedcentral.com/submit
() BioMed Central 